\title{
A STUDY ON ROLE OF OCTREOTIDE ON OUTCOME OF PATIENTS WITH ACUTE PANCREATITIS
}

\section{Dr. Vishal Lodha* \\ Dr. Rajesh Sonsale}

\section{Dr. Sandip Jadhav}

Junior Resident, Department of Surgery, Smt. Kashibai Navale Medical College and General Hospital, Narhe, Pune. ${ }^{*}$ Corresponding Author

Associate Professor, Department of Surgery, Smt. Kashibai Navale Medical College and General Hospital, Narhe, Pune.

Guide and Professor, Department of Surgery, Smt. Kashibai Navale Medical College and General Hospital, Narhe, Pune.

ABSTRACT Introduction: Mild pancreatitis is a self limiting disease, while morbidity and mortality is considerably high in cases of severe necrotizing pancreatitis. Octreotide reduces secretion, release and activation of exocrine hormones; there is collection of pancreatic hormones in duct which in return causes irreversible destruction of the exocrine and endocrine pancreatic parenchyma leading to mal-digestion and diabetes. There are lot of controversies in the treatment of acute pancreatitis, so through this study we tried to evaluate whether there is a beneficial role of octreotide or not.

Materials and Method: This case control study was done on patients admitted for the treatment of acute pancreatitis at a tertiary care hospital in Central India. This is retrospective study. The data of inpatient records were taken from the medical records department (MRD) of the hospital. The diagnosis of patients was established on basis of biochemical and radiological investigations. The patients were divided into two groups; cases and control, cases had received octreotide along with fluids (group A) controls received fluids without octreotide (group B). Symptomatic treatment was given in both the groups. Ages of the cases and controls were matched ( \pm 3 years). The statistical analysis of data was done and results were obtained.

Results: In this retrospective case control study the records of fifty two patients were selected. The mean age in Group A was 35 \pm 16.45 years and in Group B $40 \pm 17.51$ years in Group B ( $t_{\overline{A B}} 1.061 ; p$ 0.294). There were 22 males and 4 females in group $A$, while 20 males and 6 females in group B. Both the groups were comparable. All the patients in octreotide group survived while there were three deaths in control group. As far as mean hospital stay is was 10 days \pm 7.10 in group A while it was 7 days \pm 3.65 in group B. All the p values for the criteria of study are non-significant. But when we talk about percentage, $11.53 \%$ patient died in control group.

Conclusion: In our study we found that octreotide does not affect the final outcome of patients with acute pancreatitis. There is no effect on hospital stay and reduced need of analgesics in patients with acute pancreatitis. Keywords: Acute Pancreatitis; Octreotide; Hospital Stay; Mortality

\section{KEYWORDS :}

\section{INTRODUCTION}

Mild or edematous pancreatitis is a self limiting disease (Schwartz $10^{\text {th }}$ edition), morbidity and mortality is considerably high in cases of severe necrotizing pancreatitis. ${ }^{1}$ Octreotide reduces splanchnic blood flow, gastrointestinal motility, absorption of water, electrolytes and nutrients from the gut. There is evidence of abdominal pain and diarrhea in few cases. It is considered to be least effective in reducing pain in cases of acute pancreatitis. ${ }^{2}$ Octreotide inhibits stimulated pancreatic secretion and so it is useful in pancreatic diseases and pancreatic injury.

It increases the pressure at sphincter of Oddi which results in impairment of pancreatic outflow. The dysfunction of sphincter of Oddi is thought to be a cause of acute idiopathic recurrent pancreatitis. No significant change is observed in pre and post void pressure at basal sphincter of Oddi with the use of octreotide. It reduces secretion, release and activation of exocrine hormones; there is collection of pancreatic hormones in duct which in return causes irreversible destruction of exocrine and endocrine pancreatic parenchyma which leads to mal-digestion and diabetes. ${ }^{1,4}$

There is no effect on pain with the use of octreotide. ${ }^{1}$ In cases of acute pancreatitis octreotide produces contractility of sphincter of Oddi which results in retention of enzymes inside the pancreas which may be responsible for auto-digestion and further progression of disease. It reduces the complications after elective pancreatic surgery. It is reported that inhibitory effect of octreotide is lost after 7 days of its administration. There is no target drug especially for pancreatitis in initial phase of disease to fight against systemic inflammatory response syndrome. ${ }^{3,4}$ There are lots of controversies in the treatment of acute pancreatitis, so we tried to evaluate whether there is a beneficial role of octreotide or not.

\section{METHOD AND MATERIALS}

This case control study was done on patients admitted for the treatment of acute pancreatitis at Tertiary Care hospital in rural central India. The diagnosis of patients was established after biochemical and radiological investigations. The data of inpatient records were taken from the medical records department of the hospital. Due clearance from the Institutional Ethics committee was taken. The inpatient medical records of patients were noted and studied from July 2019 to June 2020 .

The hospital has many units in the department of General surgery; some of them consider use of octreotide for acute pancreatitis, while some consider fluid and symptomatic management for it so we selected this topic for retrospective research. For establishment of diagnosis, serum amylase, serum lipase levels, Ultrasonography and Computed Tomographic scan were taken into consideration. From the inpatient records of previously diagnosed patients the data was obtained. The patients were divided in two groups, Group A (Cases) consisted of patients who received octreotide, pancreatic enzyme substitutes, antacids, antiemetics and fluids and Group B (Controls) who did received pancreatic enzyme substitutes, antacids, antiemetics and fluids and no octreotide was given. The patients were chosen with age matching ( \pm 3 years) in control group. Ringer lactate and Dextrose saline were used and symptomatic management was done in both the groups. The use of analgesic more than three times a day was considered as patient not relieved of pain; the patient needed more analgesics. 
The effects studied were; hospital stay, mortality, pain, and severity of pancreatitis by amylase and lipase levels in both the groups on admission to see the intensity.

\section{RESULTS}

The results of this case control study are based on inpatient hospital records from July 2019 to June 2020. As it was a retrospective study the records of fifty two patients were acquired; the patients were divided into 2 groups; each group consisting of twenty six patients. One group received fluids with octreotide and other received fluids without octreotide. Symptomatic treatment was given in both the groups. In group A octreotide was given and in group B, octreotide was not given.

The statistical analysis was done using primer of Biostatistics Ver. 5.0 McGraw Hill 2002. Student's t-test, Fischer's Test and Chi square test was applied as it was necessary to assess the difference among two groups. The mean age in octreotide group (Group $A$ ) was $35 \pm 16.45$ years when compared with $40 \pm 17.51$ years in Group B ( $\left.t_{A B} 1.061 ; p<0.294\right)$.

Gender wise comparison showed that, there were 22 males and 4 females in octreotide group, while 20 males and 6 females in control group. Both the groups were comparable, there was no significant difference noted $(\chi 2=0.12, p<0.72$ ). All the patients in octreotide group survived while there were three deaths in control group (F test was applied, $\mathrm{p}<0.011$ ). In terms of mortality $11.53 \%$ death occurred in control group. As far as mean hospital stay was concerned it was 10 days \pm 7.10 in octreotide group while it was 7 days \pm 3.65 in control group $\left(t_{A B B}=1.1916 ; \mathrm{p}<0.061\right)$. The mean value of serum amylase in octreotide group on admission was $446 \pm 505 \mathrm{U}$ (Units) and in control group it was $452 \pm 416.39 \mathrm{U}$. The mean value of serum amylase in octreotide group before discharge was $446 \pm 505 \mathrm{U}$ (Units) and in control group it was $452 \pm 416.39$ U. The values for serum lipase were $651 \pm 466.33 \mathrm{U}$ in octreotide group and $904 \pm 784.38 \mathrm{U}$ in control group $\left(\mathrm{t}_{\mathrm{A} B}=1.414 ; \mathrm{p}<0.164\right)$. The values for serum lipase were $651 \pm 466.33 \mathrm{U}$ in octreotide group and $904 \pm 784.38 \mathrm{U}$ in control group $\left(\mathrm{t}_{\mathbb{A} / \mathrm{B}}=1.414 ; \mathrm{p}<\right.$ 0.164). All the $p$ values for the criteria of study are nonsignificant (Table 1).

Table 1 Comparison of groups Group A (Octreotide Group) and Group B (Non Octreotide Group)

\begin{tabular}{|c|c|c|c|}
\hline Characteristics & $\begin{array}{l}\text { Octreotide } \\
\text { (Group A) }\end{array}$ & $\begin{array}{c}\text { Control } \\
\text { (Group B) }\end{array}$ & Significance \\
\hline & Age & & \multirow{3}{*}{$\begin{array}{l}\mathrm{t}=-1.061 \\
\mathrm{p}=0.294\end{array}$} \\
\hline Mean & 35 & 40 & \\
\hline SD & 16.45 & 17.51 & \\
\hline & Sex & & \multirow{3}{*}{$\begin{array}{c}\mathrm{X} 2=0.12 \\
\mathrm{p}=0.72\end{array}$} \\
\hline $\mathrm{M}$ & 22 & 20 & \\
\hline $\mathrm{F}$ & 4 & 6 & \\
\hline & Outcome & & \multirow{3}{*}{$\begin{array}{c}\mathrm{f} \text { TEST } \\
\mathrm{p}=0.011\end{array}$} \\
\hline Cured & 26 & 23 & \\
\hline Death & 0 & 3 & \\
\hline & Hospital stay & & \multirow{3}{*}{$\begin{array}{l}\mathrm{t}=1.916 \\
\mathrm{p}=0.061\end{array}$} \\
\hline Mean & 10 & 7 & \\
\hline SD & 7.10 & 3.65 & \\
\hline \multicolumn{3}{|c|}{ S. Amylase (Before admission) } & \multirow{3}{*}{$\begin{array}{l}t=-0.051 \\
p=0.959\end{array}$} \\
\hline Mean & 446 & 452 & \\
\hline SD & 505.18 & 316.39 & \\
\hline \multicolumn{3}{|c|}{ S. Lipase (Before admission) } & \multirow{3}{*}{$\begin{array}{l}t=-1.414 \\
p=0.164\end{array}$} \\
\hline Mean & 651 & 904 & \\
\hline $\mathrm{SD}$ & 466.33 & 784.38 & \\
\hline
\end{tabular}

On the basis of in patients records the mean hospital stay in group $A$ was $10 \pm 7.10$ days and in group $B$ was $7 \pm 3.65$ days so it can be stated that the mean hospital stay was more in group who received octreotide but statistically it was not significant.
The pain was present in 16 patients in both the groups, as the patients received more than three doses of analgesic. Being a retrospective study, it was not possible to assess the intensity of pain and hence it cannot be said that there was greater relief of pain in group which received octreotide or not. We found there was no role of Octreotide in pain reduction.

Three patients out of 26 died in group $B$ and the reason behind it was multiple organ failure. Liver and renal functions were deteriorating; ultimately they were put on ventilator for respiratory support and circulatory support was continued, but the vitals could not be maintained and the patient collapsed. The patients were young and below 45 years of age. No statistical significance in the values was there. There were $11.53 \%$ deaths recorded in control group.

In group $A$ the mean amylase level was $446 \pm 505$ Units, in control group B it was $452 \pm 416.39$ Units, the mean lipase level in group A was $651 \pm 466.33$ Units and in control group B it was $904 \pm 784.38$ Units.

As far as hospital stay of the patient is considered the hospital stay was longer in patients who did receive octreotide. The mean hospital stay in patients in group $A$ was $10 \pm 7.10$ and the mean hospital stay in group B was $7 \pm 3.65$.

\section{DISCUSSION}

The chances of shock and ARDS (acute respiratory distress syndrome) increased in non octreotide group; there is no change in pain, intensity, its duration, hospital stay and mortality. ${ }^{5}$ In a study done by Paran et al reveals that there are high chances of sepsis and ARDS in patients not receiving octreotide, along with prolong hospital stay and high mortality. ${ }^{6.7}$ The hospital stay is shorter in patients receiving octreotide; while patients not receiving Octreotide show higher mortality. There is definitely great role of octreotide in severe acute pancreatitis. The chances of sepsis and ARDS are low in patients receiving octreotide. ${ }^{6,7}$

Benefits of octreotide observed clinically in experimental models are: Less hypoglycemia, less acidosis, reduction in pancreatic edema, little damage to pancreas and there is reduction in mortality. ${ }^{5,10,11}$ No difference is observed in levels of fasting glucose, calcium, albumin level, complete blood; picture, LDH, renal function test, blood pressure, and fever in the patients receiving octreotide or not. There pleural effusion, ascites, pancreatic edema and retroperitoneal edema is reduced in octreotide group. It is considered that if oral intake is started at early phase then serum amylase levels and pancreatic edema are evident to reduce fast. ${ }^{12}$

The findings of rebound leucocytosis, elevated serum and urine amylase level is same in both groups. There is no fall or rise in amylase secretion in patients of pancreatitis when the patient is administered with octreotide. ${ }^{9,13,14}$ Many studies concluded that along with bedside index for severity in acute pancreatitis, serial urea and creatinine guidelines can be used to manage the disease. ${ }^{15}$

There are $30-50 \%$ chances of mortality in cases of severe acute pancreatitis. ${ }^{11}$ One of the studies says that there is same mortality in both the groups and other study says that there is no difference in mortality or complications. These are again inconclusive evidences; they are nor favoring neither discouraging the use of octreotide in cases of pancreatitis. ${ }^{5,6,7}$

In our study more deaths were observed in group who did not received octreotide. It is a fact that less amount of analgesic is needed to control pain in octreotide group. It is controversial that, whether there is any change in duration of pain and intensity in octreotide and non octreotide group. ${ }^{16}$ Optimally less or more fluid produces poor outcome. . 17,18,19 $^{-19}$ 
Role of Ringer lactate can't be denied as there is reduction in systemic inflammatory response syndrome with its use. ${ }^{20}$ Previously it was thought that fluid resuscitation improves the prognosis of acute pancreatitis. Many more studies are required to make it a recommendation because; the evidences are based on theoretical, animal models, and retrospective studies. It is still doubt that which type of fluid should be given and what should be the rate of administration, it needs many more trials. ${ }^{2}$

There is a huge controversy about the use of octreotide in cases of acute pancreatitis; opinion of every study differs from another. In our study we could not find any differences in both the groups. There was no difference in hospital stay, pain and mortality, the statistical results were not significant and they were same in both the groups. But mortality was higher in patients not receiving octreotide.

\section{CONCLUSION}

Our study concludes that statistically octreotide does not play any important role in patients with acute pancreatitis. The hospital stay is almost the same, there is less mortality in octreotide group, but it cannot be statistically proven, there is no reduction in dose of analgesics in both the groups. This study on octreotide needs a lot of patients to establish its role in cases of acute pancreatitis. When we read literature of recent days, many studies reveal that the use of octreotide is controversial. So we can say that, it needs more multicentre trial, and multivariate analysis to prove the role of octreotide in cases of acute pancreatitis.

\section{REFERENCES}

1. Uhl W, Anghelacopoulos SE, Friess H, Büchler M.W. The Role of Octreotide and Somatostatin in Acute and Chronic Pancreatitis. Digestion. 1999;60 Suppl 2:23-31.

2. Parekh D. Pancreatic Ascites and Effusion Risk Factors for Failure of Conservative Therapy and the Role of Octreotide Arch Surg. 1992;127(6):707712 .

3. Jenkins SA, Berein A. The relative effectiveness of somatostatin and octreotide therapy in pancreatic disease. Alimentary Pharmacology \& Therapeutics, 1995,9: 349-361.

4. Francesco VD, Angelini G, Bovo P, Casarini MB, Filippini M Vaona B, Frulloni L, RigoL, Brunori MP, Cavallini G. Effect of octreotide on sphincter of oddi motility in patients with acute recurrent pancreatitis. Digestive Diseases and Sciences. December 1996, Volume 41, Issue 12, pp 2392-2396.

5. Fiedler F, Jauernig G, Keim V, Richter A, Bender HJ. Octreotide treatment in patients with necrotizing pancreatitis and pulmonary failure. Intensive Care Med. 1996 Sep;22(9):909-15.

6. Paran H, Neufeld D, Mayo A Shwartz I Singer P Kaplan O, Skornik Y Klausner J, Freund U. Preliminary report of a prospective randomized study of octreotide in the treatment of severe acute pancreatitis. J Am Coll Surg.1995 Aug;181(2):121-4

7. Paran H, Mayo A, Paran D, Neufeld D, Shwartz I, Zissin R, Singer P, Kaplan O, Skornik Y, Freund U. Octreotide treatment in patients with severe acute pancreatitis. Dig Dis Sci. 2000 Nov; 45(11):2247-51.

8. Poon RT, Fan ST. Antisecretory agents for prevention of post-ERCP pancreatitis: rationale for use and clinical results. JOP. 2003 Jan; 4(1):33-40.

9. Kisli E, Baser M, Aydin M, Guler O. The role of octreotide versus placebo in the prevention of post- ERCP pancreatitis. Hepatogastroenterology. 2007 JanFeb; (73):250-3.

10. Paran H, Klausner J, Siegal A, Graff E, Freund U, Kaplan O. Effect of the somatostatin analogue octreotide on experimental pancreatitis in rats. J Surg Res. 1996 May;62(2):201-6.

11. McKay C. Baxter J. Imrie C. Necrotic acute pancreatitis in the intensive care unit: a A randomized, controlled trial of octreotide in the management of patients with acute pancreatitis. Rev Gastroenterol Peru. 2010 JulSep;30(3):195-200

12. Karakoyunlar O, Sivrel E, Tanir N, Deneçli AG. High dose octreotide in the management of acute pancreatitis. Hepatogastroenterology. 1999 MayJun;46(27):1968-72.

13. Nikou GC, Arnaoutis TP, Giamarellos-Bourboulis EJ, Samolada O, VafiadisZouboulis I, Katsilambros N, Arvanitakis C.The significance of the dosage adjustment of octreotide in the treatment of acute pancreatitis of moderate severity. Hepatogastroenterology. 2001 Nov-Dec;48(42):1754-7.

14. Arvanitidis D, Hatzipanayiotis J, Koutsounopoulos G, Frangou E The effect of octreotide on the prevention of acute pancreatitis and hyperamylasemia after diagnostic and therapeutic ERCP. Hepatogastroenterology. 1998 JanFeb; 45(19): 248-52

15. Lee WS, Huang JF, Chuang WL. Outcome assessment in acute pancreatitis patients. Kaohsiung J Med Sci. 2013 Sep;29(9): 469-77.

16. Trepte CJ, Bachmann KA, Stork JH, Friedheim TJ, Hinsch A, Goepfert MS, Mann O, Izbicki JR, Goetz AE, Reuter DA. The impact of early goal-directed fluid management on survival in an experimental model of severe acute pancreatitis. Intensive Care Med. 2013 Apr;39(4):717-26.

17. Marton J, Szasz Z, Nagy Z, Jarmay K, Takacs T, Lonovics J, Balogh A, Farkas G. Beneficial effect of octreotide treatment in acute pancreatitis in rats. Int $J$
Pancreatol. 1998 Dec;24(3):203-10

18. Trikudanathan G, Navaneethan U, Vege SS. Current controversies in fluid resuscitation in acute pancreatitis: a systematic review. Pancreas. 2012 Aug; 1 1(6):827-34.

19. de-Madaria E.Fluid therapy in acute pancreatitis. Gastroenterol Hepatol. 2013 Aug 26. pii: S0210-5705(13)00069-1]

20. Haydock MD, Mittal A, Wilms HR, Phillips A, Petrov MS, Windsor JA. Fluid therapy in acute pancreatitis: anybody's guess. Ann Surg. 2013 Feb;257(2):182-8.

21. Wu BU, Hwang JQ, Gardner TH, Repas K, Delee R, Yu S, Smith B, Banks PA Conwell DL. Lactated Ringer's solution reduces systemic inflammation compared with saline in patients with acute pancreatitis. Clin Gastroenterol Hepatol. 2011 Aug; 9(8):710-717. 